\title{
An appraisal of the of eco-climatic characteristics in Northern Nigeria
}

\author{
AbdulKadir A. ${ }^{1 \star}$, Usman M. T. ${ }^{1}$, Shaba A. H. $^{2}$ and Saidu S. ${ }^{1}$ \\ ${ }^{1}$ Department of Geography, Federal University of Technology, PMB 65, Minna, Bosso Campus 920003, \\ Niger State, Nigeria. \\ ${ }^{2}$ Strategic Space Applications, National Space Research and Development Agency (NASRDA), \\ P.M.B. 437, Garki, Abuja, Nigeria.
}

Accepted 1 August, 2013

\begin{abstract}
The character of the sub-regional eco-climatic zones has possibly changed as suggested in the dwindling fortune of agricultural productivity, documented changes in vegetation and freshwater resources and rising poverty levels especially in the hitherto productive Northern Nigeria. To determine and map the changes, if any, in these eco-climatic characteristics is therefore important for general planning. This study is using rainfall and temperature data (1950-2006) to determine factors of rainfall effectiveness; onset dates, cessation dates, hydrologic growing season (HGS), monsoon quality index (MQI) and aridity index (Al); summarizing and ranking them using numerical identifiers for the interpretation of the various moisture situations, to assess the eco-climatic characteristics in the northern Nigeria. A multi-temporal database has been developed for the factors and classes have been defined using quantitative definitions for the time series. The point data have been transformed to spatial data and subjected to geospatial analysis. The results so far reveal variability in the effects of each factor on eco-climatic zonation and it is anticipated that integrating these derived climatic parameters and remotely sensed (vegetation dynamics) data using GIS techniques, is crucial for water management and attainment of food security.
\end{abstract}

Key words: Eco-climatic, moisture effectiveness, surface, principal component analysis, environmental quality.

\section{INTRODUCTION}

Globally, increased rainfall variability, climate change and increased human activities have being and will continue to adversely modify the natural resource and the environment as a whole. Climate exerts a strong influence on relevant socio-economic sector and people's livelihood in sub-humid and semi arid zones of northern Nigeria where the drying condition have being on the increase. These changes are occurring at unprecedented rate thereby drastically reducing bio-productivity of the physical environment. This uncoordinated and undocumented process of change is a treat to food security and apparent poverty level typical of northern Nigeria. Environmental degradation also contributes significantly to food insecurity (FAO, 1996). Desertification of the northern region has being severely altering the traditional climatic and eco-climatic zones resulting to recurring

${ }^{*}$ Corresponding author. E-mail: abuzaishatu@futminna.edu.ng.

Abbreviations: Al, Aridity Index; C, cessation; FAO, Food and Agricultural Organization; FCT, Federal Capital Territory; GIS, geographic information system; HGS, hydrologic growing season; MEC, moisture effectiveness classes; MEM, moisture effectiveness map; MEZ, moisture effectiveness zones; MQI, monsoon quality index; NIMET, Nigeria Meteorological Agency; $\varnothing$, onset; PCA, principal component analysis. 
crop failure, giving rise to sharp increase in the prices of agricultural products, hunger, sickness, malnutrition, starvation and livestock death in extreme cases.

The geographical location of the northern Nigeria is generally prone to drought, wind and water erosion, thereby promoting geo-environmental degradation. This region is a marginal land, where crops experience moisture stress and often fail mainly as a result of the effect of the repeated prolonged drought. Although agriculture is the major occupation in this region, desertification, repeated drought, crop failure and southward migration of the inhabitant signal is the fact that food security is threatened.

The escalating variability in rainfall distribution, deforestation and degradation of natural resources in the zone has significant eco-climatic and socio economic impacts. Understanding of the nature and future climate change has led to a realization that significant future impacts are inevitable and increased efforts towards understanding the process of adaptation to the threatened impacts are required (Adger, 2001). These cumulative effects of rapid depletion of natural resources in the region, through over exploitation and variability in the distribution pattern of rainfall have drastically affected the quality of the biotic and abiotic components in the zones.

Accordingly, this constitutes potential treat for the attainment of sustainable develop-ment. Peter (1998) states that a wide range of ecological and human crises result from inadequate access to, and the inappropriate management of the resources. Conse-quently, adequate information on the eco-climatic charac-teristics is vital in proffering solutions, combating the problem of food security in the entire northern Nigeria and a pathway for the attainment of sustainable socio-economic development in the region.

Rainfall is the principal nourishment for the terrestrial eco-system at the same times the requirement for plant and animal growth; consequently, it is a primary determining factor for eco-climatic and agro-climatic zonation. The eco-climatic and agro-climatic maps used in the zone are still the traditional maps base on conventional rainfall totals and mean temperature values. Adefolalu (1986b), Usman (2000), Zeewdu and Peter (2004) and Srikantha and Uditha (2004) affirmed the need for additional rainfall characteristics in identifying plant moisture stress other than rainfall amount. Furthermore, rainfall totals are on the increase while rainy days are declining (Tennant and Bruce, 2002). Therefore, defining moisture condition using rainfall amount may be grossly inadequate and inefficient to capture the effect on eco-climatic zonation as might be expected using other characteristics of rainfall; onset, cessation dates, hydrological growing season, moisture quality and aridity index.

Then, challenges of erratic, recurring rainfall variability have adversely affected moisture quality in the zone thereby triggering aridity. David and Chasca (2005) considered climate change as 'special' amongst livelihood disturbing factors in the developing world. In Nigeria, history has proved that drastic changes in rainfall pattern have effect on agricultural productivity, disappearance of the famous groundnut pyramid in this belt follow rainfall fluctuation of 1970s.

Lázaro et al. (2001) mentioned that in order to understand the behaviour of ecosystems in semi-arid areas, rainfall must be analyzed over time. These have necessitated the appraisal of the eco-climatic characteristics other than rainfall totals and ranges whose maps has being in use over a century. Similarly, Sui-Lin and Chi-Fai (2010) identified a multifaceted strategy for the applications of science and technology, as a part of the solution, in defeating world hunger.

Also, Kufoniyi and Akinyede (2004) concluded that the fuel driving the engine of growth and sustainable development of any nation is the nation's access to reliable and adequate geospatial information. Consequently, the present study generate, compare and integrates spatial variability of eco-climatic characteristic to derived moisture effectiveness map of the zone, as pathway towards the attainment of food security and sustainability of the physical environment in northern Nigeria.

\section{Study area}

Northern Nigeria is located between Longitudes $3^{\circ}$ and $15^{\circ}$ East and Latitudes $9^{\circ}$ and $14^{\circ}$ North. Northern Nigeria is a political definition use to describe all states that are fully located or partially located (middle belt) in the northern portion of the country. The states located in this zone are Sokoto, Kebbi, Zamfara, Kastina, Kano, Jigawa, Yobe, Borno, Gombe, Bauchi, Kwara, Plateau, Adamawa, Niger, Federal Capital Territory (FCT), Nassarawa, Taraba, Kogi and Benue.

The climate is characterized by alternate wet and dry seasons in response to the changes in pressure patterns, the rainy season in this region is associated with late onset and earlier cessation, the onset and cessation are also characterized by destructive storms which destroy life and property. The seasonal and latitudinal variations affect diurnal and seasonal temperature ranges, the highest maximum air temperature is recorded in the northern part usually areas north of lat $9^{\circ}$ and occur in March /April and minimum temperatures are recorded in December/January North of lat $9^{\circ} \mathrm{N}$.

The general relief of this belt is between 300 to $900 \mathrm{~m}$, except the Niger-Benue trough, Sokoto and Chad Basins that are below $300 \mathrm{~m}$. Northern Nigeria is dominated by savanna vegetation types; Guinea, Sudan and Sahel savanna, the density of trees and grasses decrease northwards res-ponding to climatic conditions. Agriculture is the most dominant economic activity in the region. 
Table 1. Multi-temporal data summary and interpretation scheme.

\begin{tabular}{ccc}
\hline Factor classification & Interpretation basis (C, HGS, AI,) & Interpretation basis( $\varnothing \&$ MQI) \\
\hline 1 & $5 \& 4 \geq 70 \%, 1,2, \& 3 \leq 30 \%$, & $1 \& 2=0,3 \leq 20,4 \geq 40 \& 5 \geq 40$ \\
2 & $5 \& 4 \geq 50,3 \geq 40,1 \& 2 \leq 20$ & $1,2 \& 3 \geq 40,4 \geq 40 \& 5 \leq 20$ \\
3 & $5 \& 4 \geq 20,3 \geq 50,2 \& 1 \leq 30$ & $1 \& 2 \geq 20,3 \geq 50,4 \& 5 \leq 30$ \\
4 & $5,4 \& 3 \geq 40,2 \geq 40 \& 1 \leq 20$ & $1 \& 2 \geq 50,3 \geq 40,1 \& 2 \leq 20$ \\
5 & $5 \& 4=0,3 \leq 20,2 \geq 40 \& 1 \geq 40$ & $1 \& 2 \geq 70 \%, 3,4, \& 5 \leq 30 \%$ \\
\hline
\end{tabular}

\section{METHODOLOGY}

Daily rainfall and temperature records (1950-2006) for 12 selected meteorological stations: Minna, Zaria, Yola, Maiduguri, Bauchi, Sokoto, Yelwa, Kano, Jos, Gausau, Nguru, and Katsina were collected. These data were used to derive vital rainfall characteristic and moisture quality in the belt: onset, cessation, hydrological growing season (HGS), moisture quality and aridity index in zones. These were determined using intra-seasonal rainfall monitoring index (IRMI-) Usman and Abdulkadir (2012), moisture quality index (MQI-) Usman, 1999) and potential evapotranspiration (ETO Hargreaves and Samani, 1985). The computed derived parameters were summarized, analyzed and classified using SPSS software. Numerical identifiers were adapted for the interpretation of the various moisture effectiveness classes (MECs): very good, good, fair, poor and very poor zones (1, 2, 3, 4 and 5). Multi-temporal database was developed for the five factors (AI, C, HGS, MQI and $\varnothing)$. Classes were defined for each factor using multi-temporal data summary and interpretation scheme for quantitative definitions of time series data, 1950-2006 (Table 1).

A geospatial database was developed using the above interpretation scheme for visualizing each factor's rainfall effectiveness: onset $(\varnothing)$, cessation dates $(C)$, hydrologic growing season (HGS), aridity index ( $\mathrm{Al}$ ) and monsoon quality index (MQI). In addition, a geo-reference base map for northern Nigeria was digitized and the point data were transformed to spatial data. All the point data (multi-temporal) for all the factors were transformed into $\mathrm{X}, \mathrm{Y}$ and $\mathrm{Z}$ (longitude, latitude and factor) using Kriging geostatistical defaults in SURFER 8 to produce an accurate grid of the entire factors. These grids were converted to ASCII XYZ data and imported into Idrisi Andes where they were converted to IDRISI vector point files. The vector point files were interpolated to full surface layers for the five factors. These surfaces were them exported to ArcGIS 9.2 through Idrisi Andes Geotiff conversion option. These were subjected to further geo-spatial analysis using spatial analyst module. The base area map was used to extract the study area from the surfaces and the surface maps were reclassified using moisture effectiveness classes (MECs) to derived moisture effectiveness zones (MEZ). Principal component analysis was used to compress the data, identify the variance and relationship between the eco-climatic factors, finally the relation was used to integrate and reclassified the variance in the eco-climatic characteristic using supervised classification.

\section{RESULTS}

The derived eco-climatic characteristics (AI, C, HGS, MQI and $\varnothing$ ) maps of the northern Nigeria reveal climatic variability typical of the rainfall distribution in the region. López et al. (2008) observed that water availability is discontinuous and highly variable. These factors captured moisture stress of the sub-humid and dry ecosystem at different levels, such that the quality of the biological and economic resources uncertainty are apparent. These surface maps depict the spatial variability that characterized the ecological zone, five or four MECs were identified for the entire factors and the moisture effectiveness generally decreases north wards. In addition, there is variability in the number MECs captured; AI, MQC and HGS captured five while onset and cessation captured four classes each.

The surface index maps were quantitatively reclassified, to depict the spatial extent of the eco-climatic factors moisture effectiveness zones, five or four MEZs were identified for all the factors and the moisture effectiveness generally decreases north wards. In addition, there is variability in the number of MEZs captured; AI, HGS, MQI capture five MEZs while onset and cessation captured four classes each. Onset map uncover the late effective onset of rain that characterized the region, as there was no earliest onset rainfall zone while cessation does not indicate extremely early rainfall cessation in the zone. Furthermore, these derivative maps show the extent of each MEZ for each factor; the worst classes are dominant to extreme north while the best are to the south and the central parts are mostly moderate as evident in the derived eco-climatic maps (Figures 1 to 5).

Aridity index map recognized five moisture effectiveness zones across the belt; lowest, low, high, very high and extremely high.

MQI portrayed five MEZs: extremely deficient, very deficient, deficient, adequate and abundant moisture effectiveness zones. The hydrological growing season unveils five moisture effectiveness zones: longest, long, short, very short and extremely short hydrological growing season.

Real monsoon onset effectiveness map depicted four moisture zones: extremely late, very late, late and early indicating the severity of rainfall onset across the region. Similarly, cessation moisture effectiveness map identified four moisture effectiveness zones: latest, late, early and very early cessation zones. Onset map reveals the late effective onset of rain that characterized the whole belt, as there was no best onset moisture effectiveness class (very good), particularly the northeast and northwest have very poor rainfall-related onset. Cessation shows there was no zone with very poor cessation moisture effectiveness zone, signifying that cessation is less stressful across the zone. Furthermore, these derivative maps confirms increase moisture stress northwards; the 


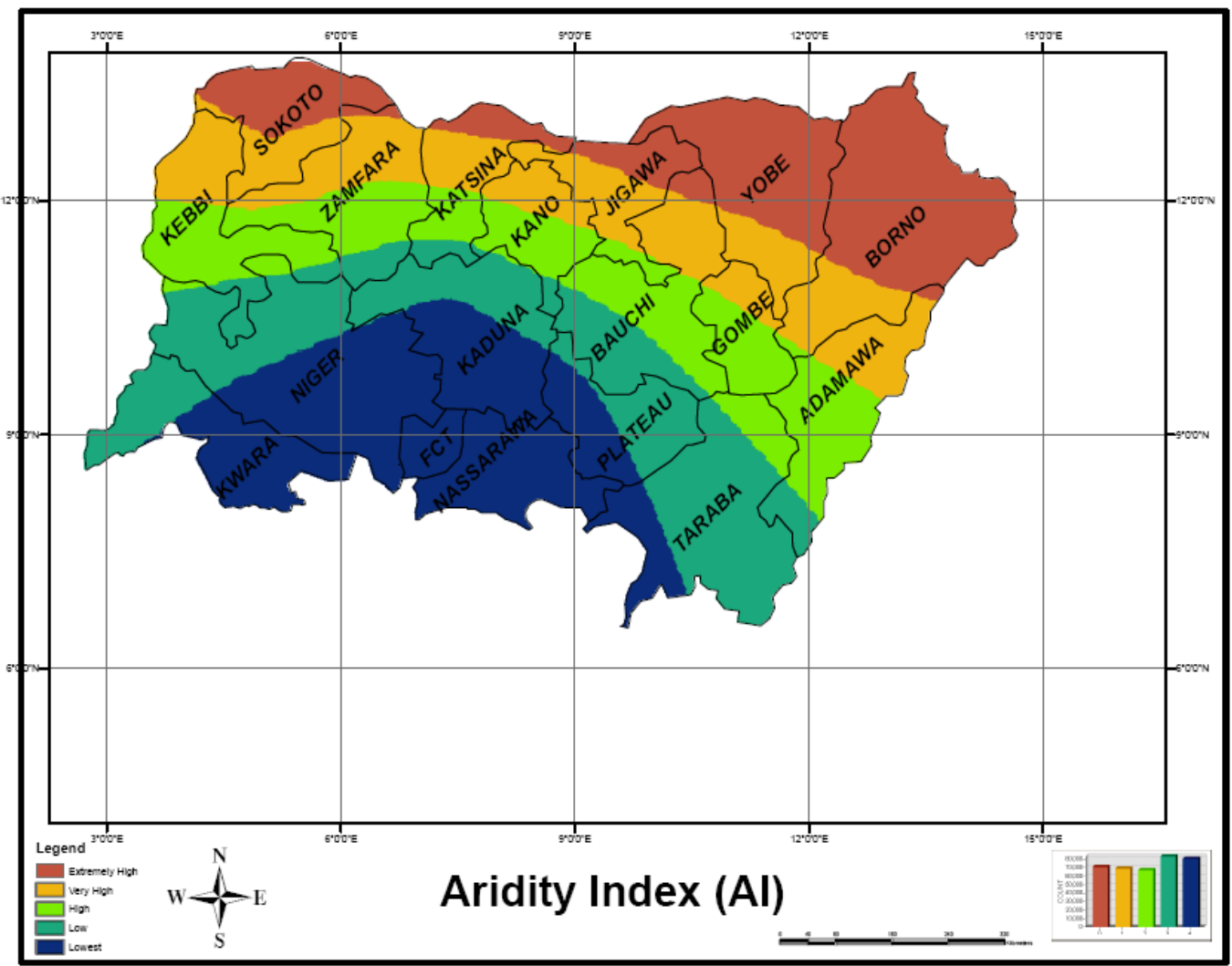

Figure 1. Aridity index map.

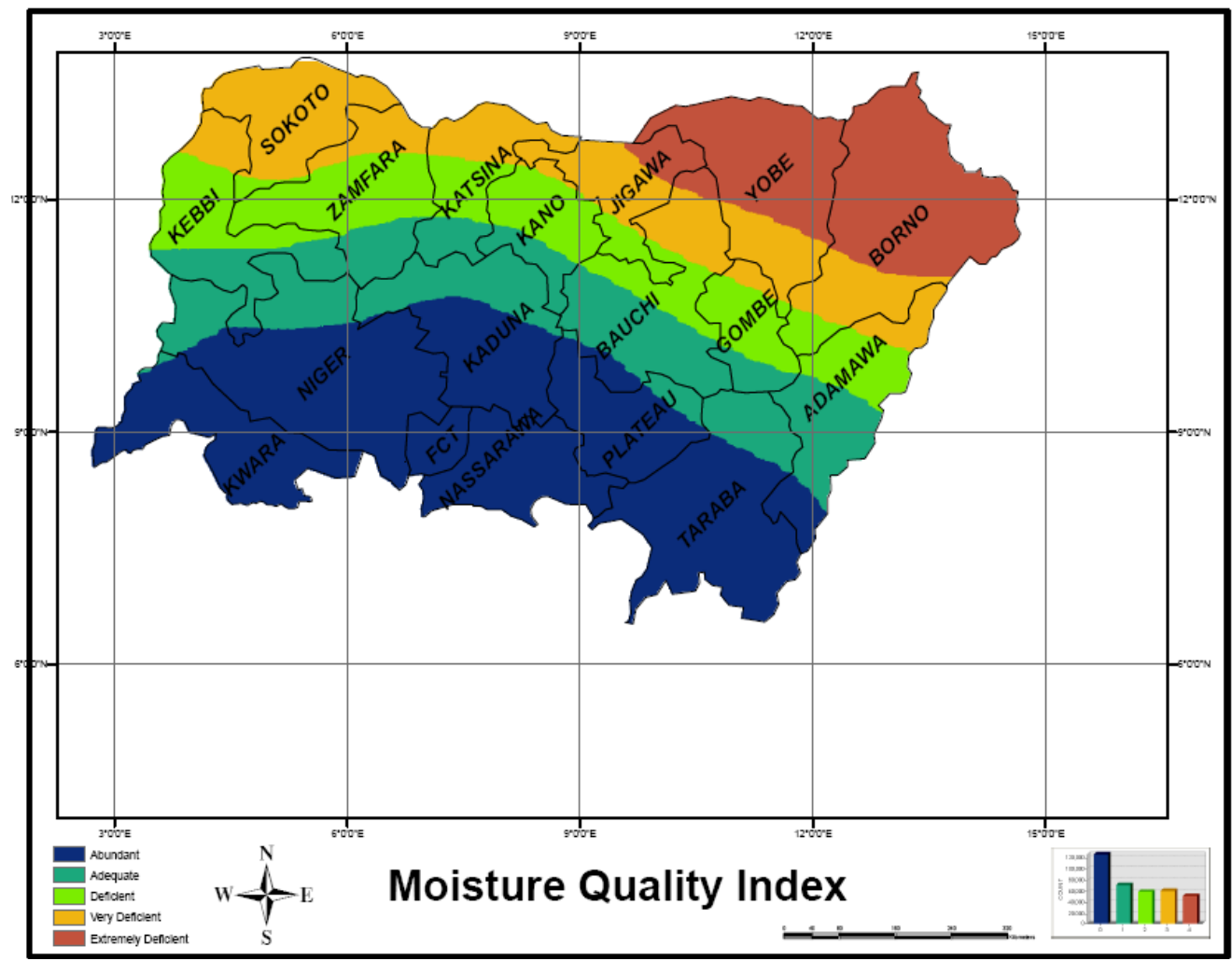

Figure 2. Moisture quality index map. 


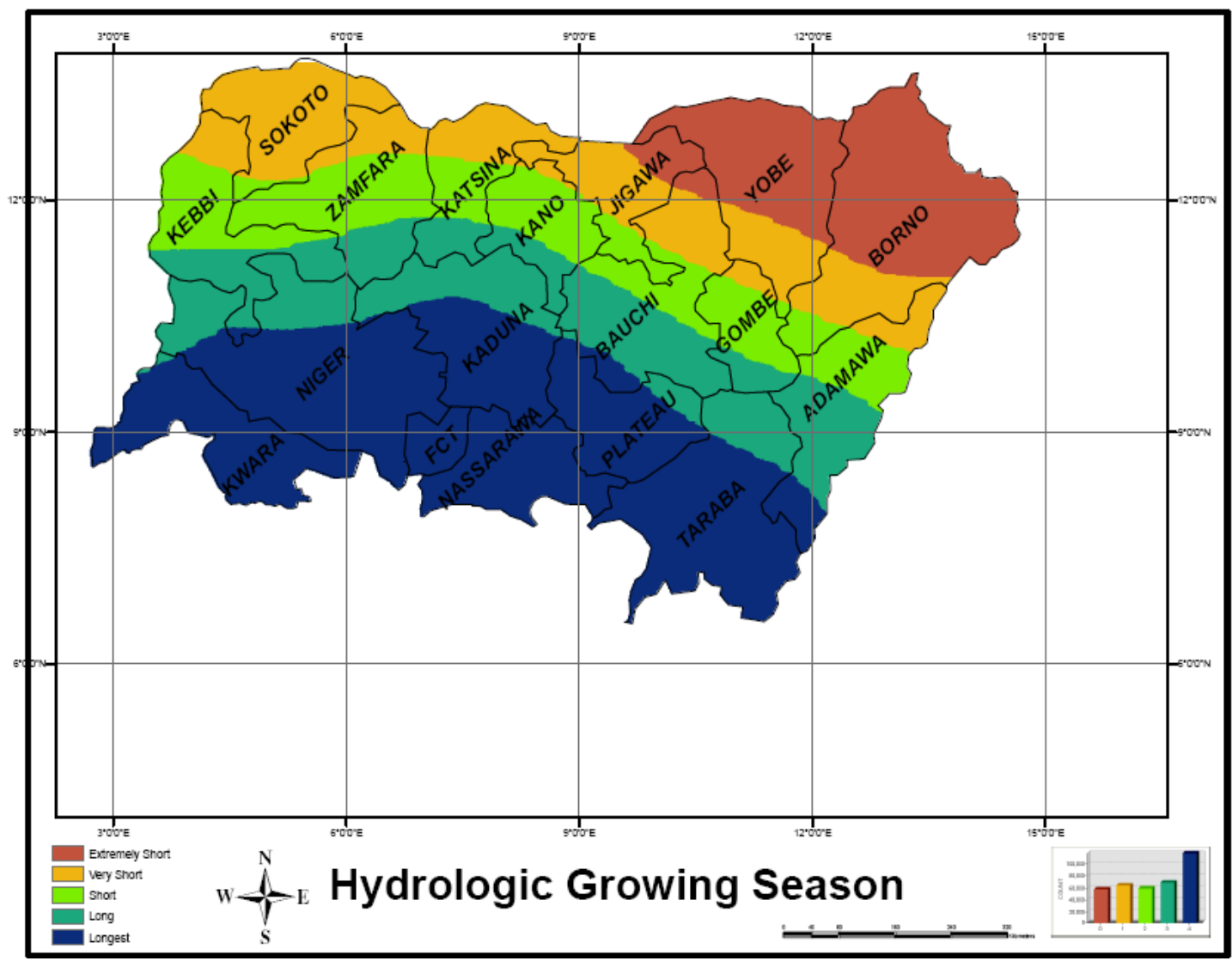

Figure 3. Hydrologic growing season map.

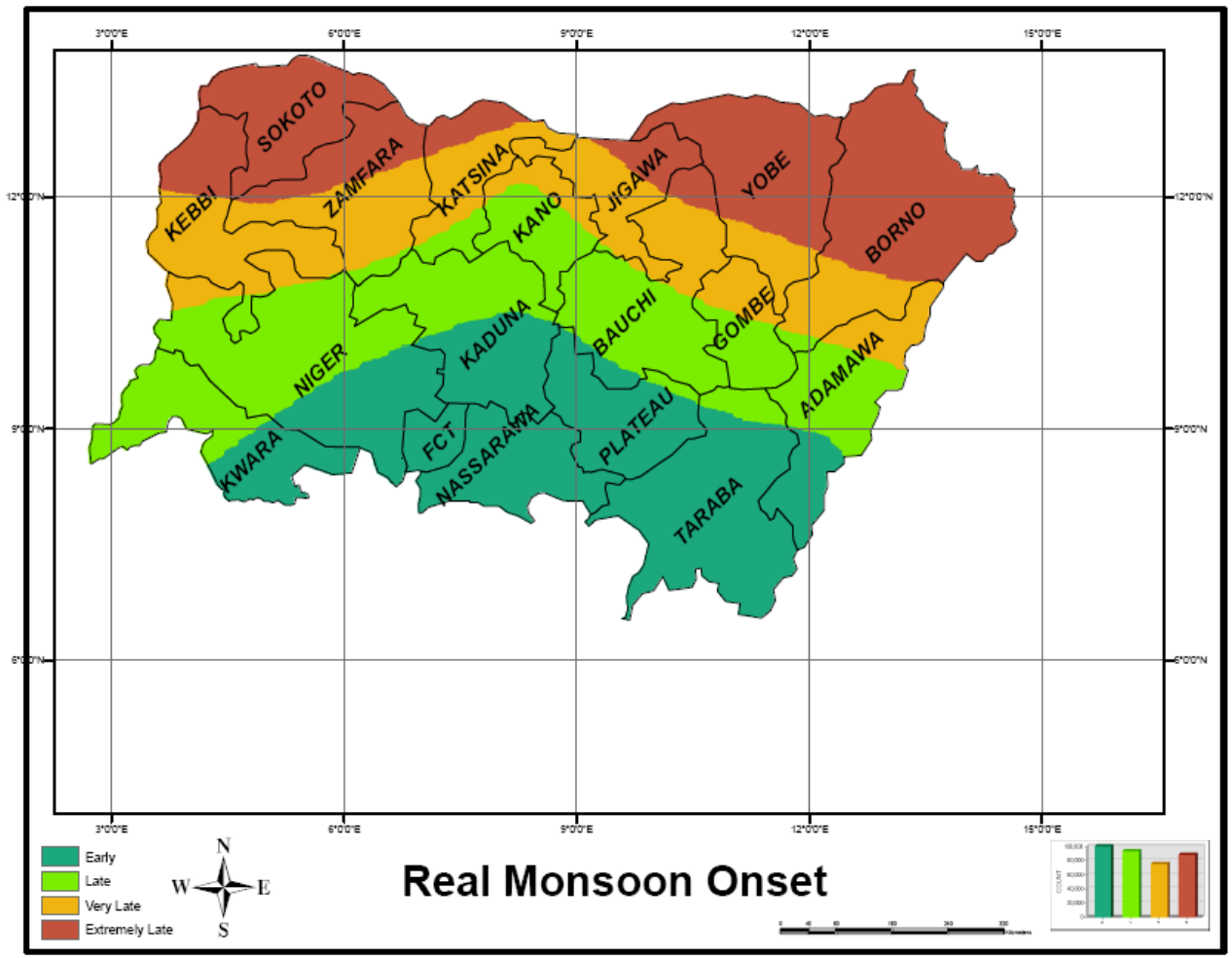

Figure 4. Onset map. 


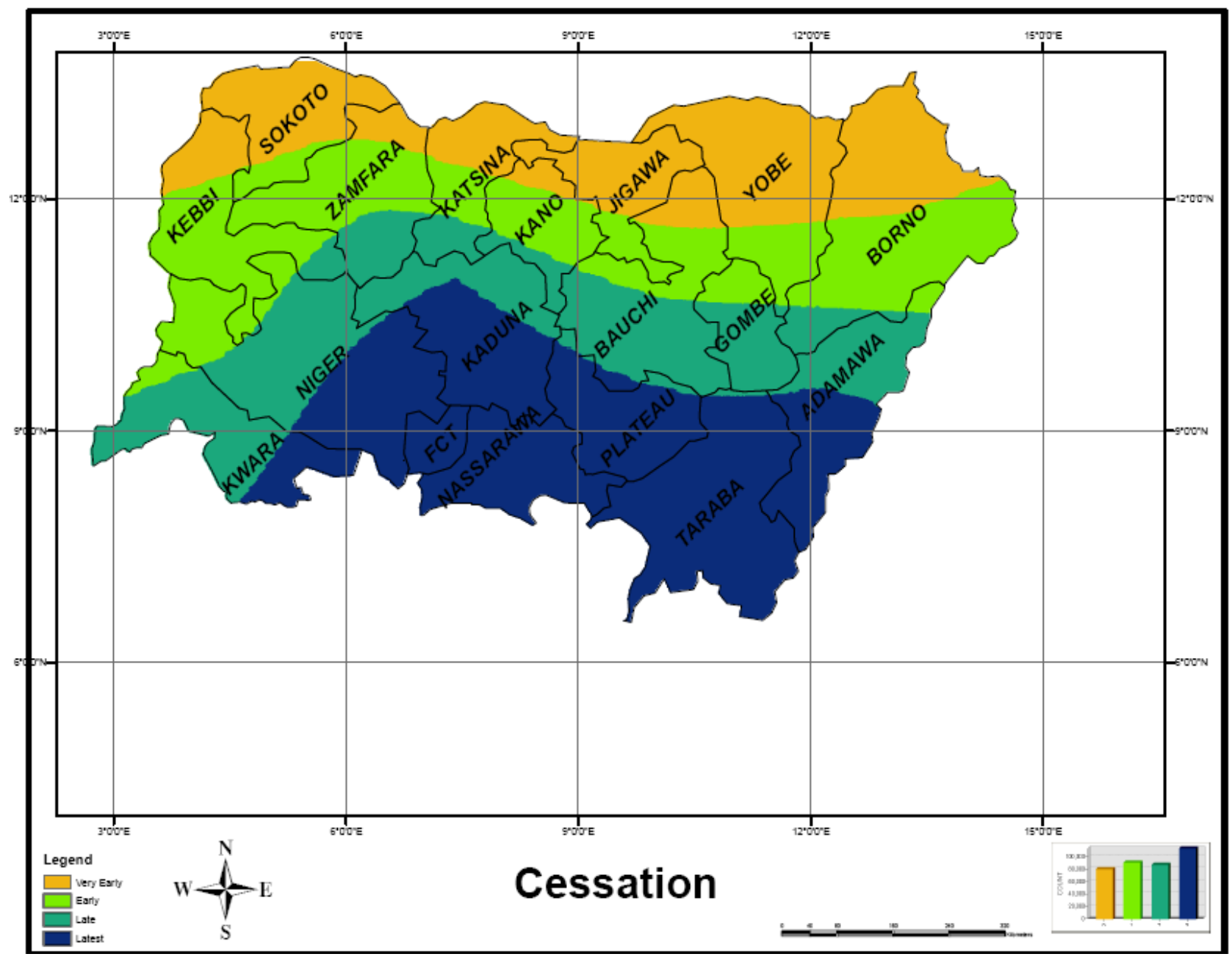

Figure 5. Cessation map.

worst classes are dominant to extreme north, while the best are to the south and the central parts are mostly moderate.

\section{Principal component analysis}

Principal component analysis (PCA), identified the union that exists between the two extreme MEZs (the best and worst) although, the intersection shows the relationship that exists between all the factors as indicated in the overlap of the intermediate classes. This signal the fact that additional techniques will be essential for the identification and delineation of these middle classes as apparent from PCA (Figure 6). To resolve this, The PCA was reclassified using supervised classification which uses union and intercessions of the various factors MEZs as an essential fact for integrating and reclassifying the factors and derives moisture effectiveness map (Figure 7).

\section{Moisture effectiveness map}

The intersections of the various factor's MEZs serve as basis for integration and reclassification of the PCA to derive moisture effectiveness maps (MEM). Supervised classification of the PCA identified five MEZs: extremely deficient, very deficient, deficient, adequate and abundant moisture zones as evident in derived moisture effectiveness map Figure 7.

The MEM identified five moisture quality zones, extremely deficient, very deficient, deficient, adequate and abundant. Abundant moisture zone comprises, FCT, Nassarawa and southern part of Kwara, Niger, Plateau, Taraba and Kaduna State. Adequate moisture zone encompasses Northern Kwara, Niger, Plateau, Taraba and Kaduna State and southern Bauchi and Adamawa state. Deficient moisture zone covers Northern Bauchi and Adamawa state, southern Gombe, Kebbi, Zamfara and Kano State. Very deficient moisture zone include northern Gombe, Kebbi, Zamfara and Kano State and southern Sokoto, Katsina, Jigawa, Yobe and Borno state. The extremely deficient moisture zone comprises the extreme north. The moisture effectiveness decreases progresssively northwards (the lower latitude are wetter than the higher ones as evident in Figure 7); thereby providing fundamental information for moisture effectiveness adaptation. 


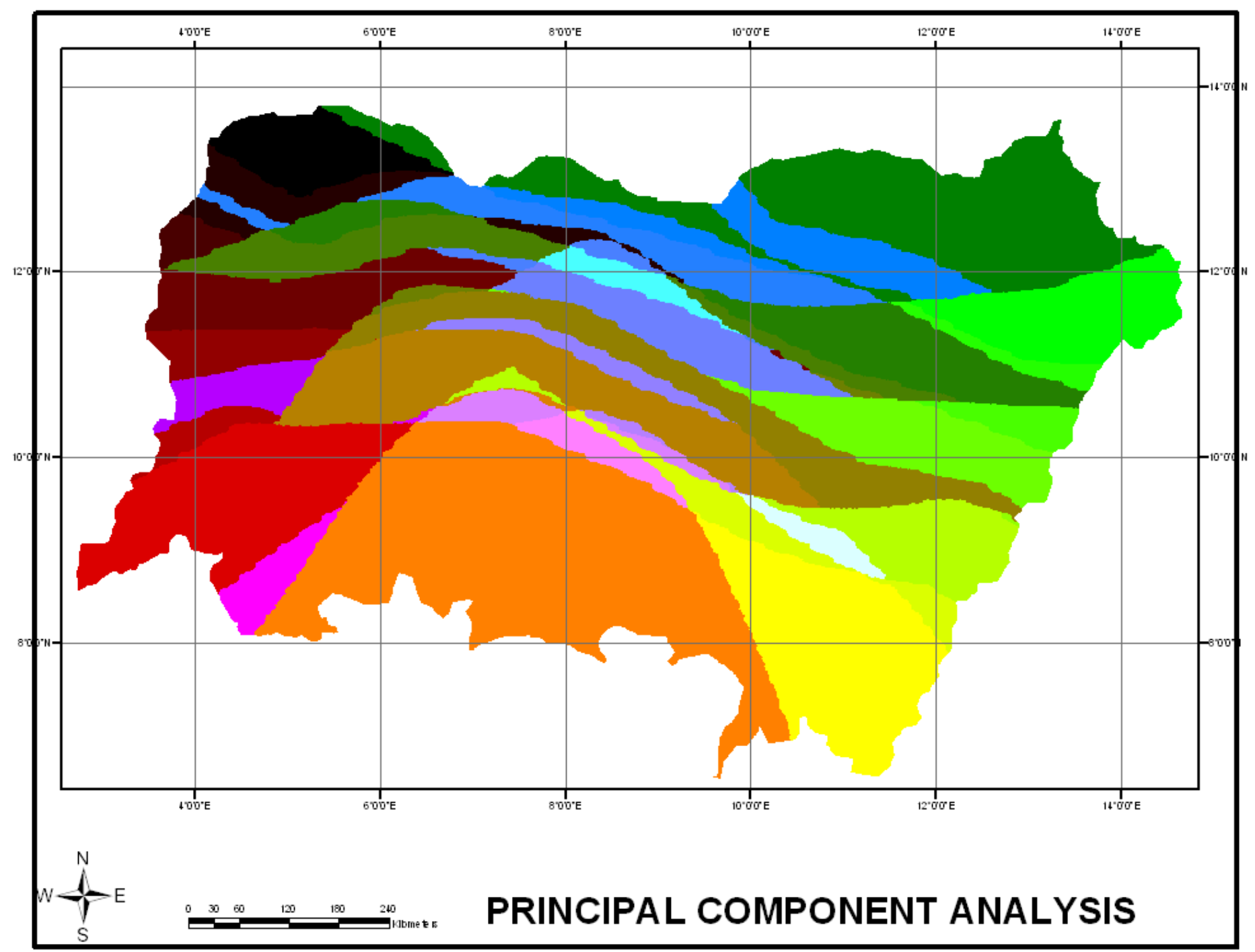

Figure 6. Principal component analyses.

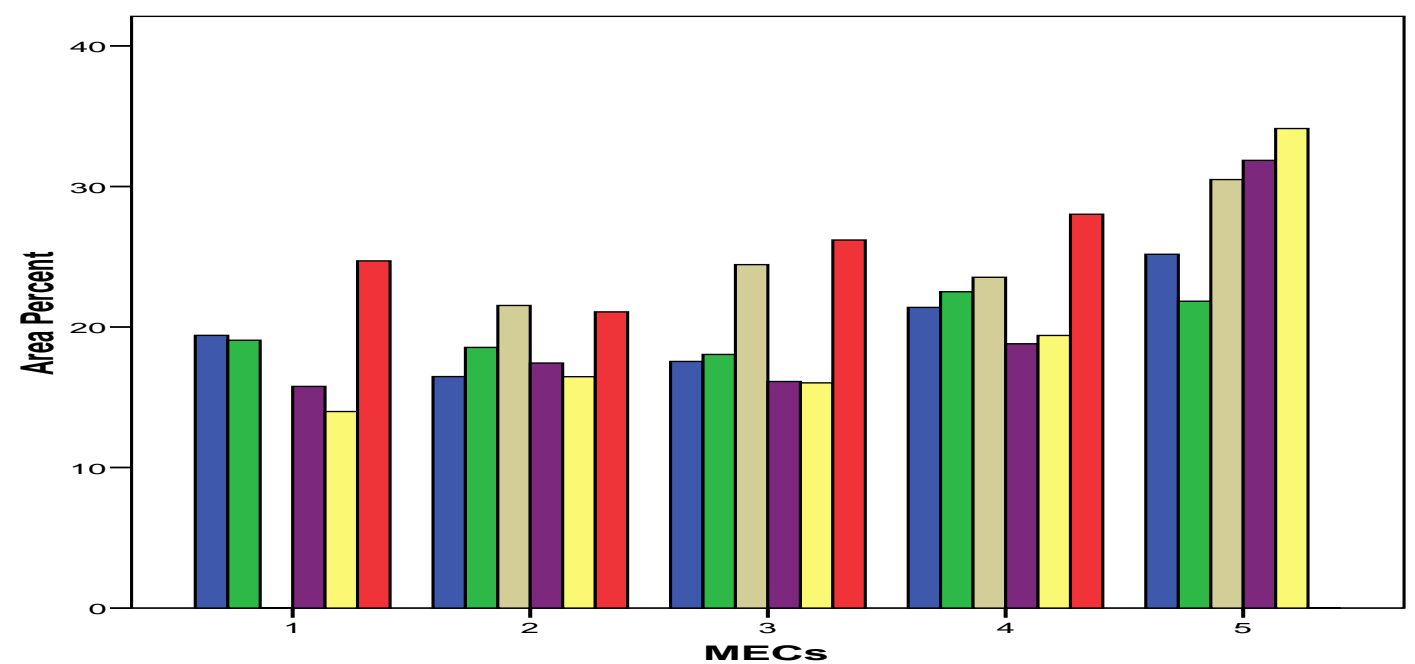

MEM

Al'

CESSATION

Mal

ONSET

Figure 7. Eco-climatic factors moisture effectiveness zone and MEM comparison. 


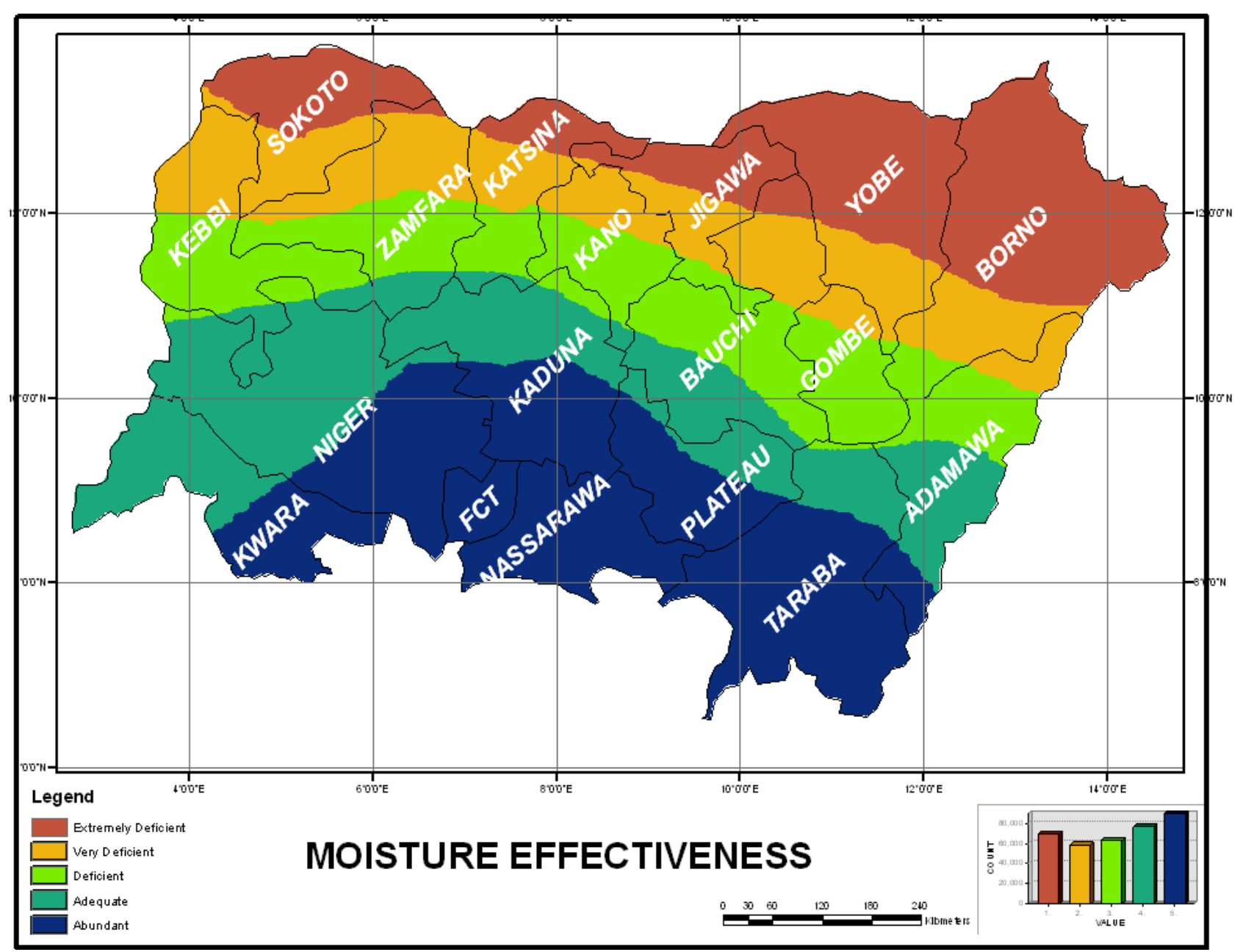

Figure 8. Moisture effectiveness map (MEM).

Table 2. Pearson correlation relationships between moisture effectiveness and eco-climatic factors.

\begin{tabular}{lc}
\hline Eco-climatic factor & Relationship with MEM \\
\hline Aridity index & 0.8 \\
Cessation & 0.9 \\
Hydrologic growing season & 0.9 \\
Onset & 0.8 \\
Moisture quality index & 0.9 \\
\hline
\end{tabular}

Furthermore, comparing the spatial extend of moisture effectiveness zones and eco-climatic factors using multiple graphs (Figure 8), unveil the spatial variability associate with the entire factors moisture effectiveness Zones and the moderating effect of MEM. This justified the need for integration and classification in smoothing the variability that characterized the moisture effectiveness as well as providing adequate information on the state of the environment. Understanding the state of the environment is crucial for the attainment of sustainable development; this will enhance the sustainability of biotic and the abiotic resources thereby providing optimal environment for sustainable agriculture.

An investigation of the relationship that exists between MEM and entire factors of eco-climatic characteristics map shows that there is strong positive relationship $(\geq 0.8)$ between the factors and the derived eco-climatic map (Table 2). Also, the regression analysis confirms that the MEM is a good predictor of the independent variable since R square change is 0.9 , thatis, $90 \%$ of MEM can be explained by the factors. Hence, a pathway for achieving adequate information to be applied in developing sustainable practices as climatic variation is fundamental to environmental quality and food security in the zone.

\section{DISCUSSION}

The factors, moisture effectiveness indices and maps (1 to 5) illustrate the spatial extents of each factor moisture effectiveness classes throughout northern Nigeria and the challenges for the sustainability of the physical envi- 
ronment. The physical consequences of moisture deficit and steady deterioration of the physical environment has shown the need to provide accurate information designed towards the achievement of sustainable development. With this result, the entire northern Nigeria is vulnerable to crop failures as vast proportion of the region is characterized by varying levels of deficient moisture quality, late onset, early retreat of rainfall and shorter hydrologic growing season that were hitherto obvious. Srikantha and Uditha (2004) identified decline in the numbers of rainy days.

These are disastrous to agriculture, as delayed onset often leads to late planting of crops, while premature cessation and shorter HGS leads to wilting and dryness of the crops before maturity and consequently, poor yield. Onset, cessation and length of the hydrologic growing season (HGS) are more critical to plant (Adefolalu, 1986a). High aridity index and moisture quality reduce bio-productivity and all these endanger food security. Generally, the entire surface map affirms that the ecoclimatic features are extremely variable and potentially associated with different forms of economic and environmental disruption (stress). The scenario calls for identifying reliable and adequate information on the state of the environment, using derived remotely sense data in mitigating water-related emergencies, providing safe access to water and combating desertification which is typical feature of Northern Nigeria.

The PCA spelt out the union between the features of the best and worst MEZs while the intersection between the various classes defining the relationship between the various factors. The lack of union particularly between the intermediate MEZs and the intersection between these classes also signals the fact that all the factors have certain unique features and have some relationship as evidenced in the overlap of the MEZs. Leonard and Felix (1998) showed that temporal and spatial characteristics are vital in change detection and mapping. Thus, this necessitates the use of other available techniques for smoothing this variability to provide adequate information on the state of the environment for enhanced rural livelyhood. Generally, MEZs do not vary in the same way. Specifically, very early onset does not necessarily imply very good moisture quality or aridity index. As a result, integration of all the factors with biophysical state of the environment (derived from satellite images) using empirical relations should be the basis for improved management of the vital resources (land and water). This will give an insight into specific management actions that will minimize the progressive ecological degradation and enhance food security in the region and the county at large.

The derived MEM indicates that moisture effectiveness across the region decreases progressively northwards as expected (Figure 7). Underscoring why the extreme north is characterized by extremely deficient moisture and very deficient moisture zone, this extends to about lat. $12^{\circ} \mathrm{N}$ and lat. $10^{\circ} \mathrm{N}$ in the northwest and northeast, respec- tively. The integration of the eco-climatic characteristics using GIS provide fundamental information for moisture stress and adaptation strategy in the region, is a signal by the strong positive correlation between the factors and MEM along with a regression analysis returning $R^{2}$ to $90 \%$. Since climatic variation is fundamental to environmental quality and food security, such information will enhance the sustainability of biotic and the abiotic resources and provide an optimal environment for sustainable agriculture. Furthermore, the general positive relationships that exist between the factors and moisture effectiveness map confirm that all these factors are fundamental in the identification of soil moisture stress in the zones.

The eco-climatic factors moisture effectiveness maps visualized illustrates the spatial extents of each factor moisture effectiveness zones throughout the northern Nigeria and the challenges for the sustainability of the physical environment. By this result, the entire northern Nigeria is vulnerable to crop failures as vast proportion of the region is characterized by deficient moisture quality, late onset, early retreat of rainfall and shorter hydrologic growing season that were hitherto obvious. These are disastrous to agriculture: high aridity index and poor moisture quality reduce bio-productivity and all these endanger food security. Generally, the entire surface map affirms that the eco-climatic features are extremely variable and potentially associated with different forms of economic and environmental disruption (stress). The scenario calls for the need for adoption of space technologies for identifying reliable and adequate information on the state of the environment.

\section{Conclusion}

Surface interpolation of the derived parameters (onset, cessation, hydrologic growing season, aridity index and vegetation index) offered fundamental information for visualizing and understanding the eco-climatic characteristic. The plotted and classified eco-climatic characteristics provide adequate information on the moisture effectiveness in the zone. Principal components analyses compress the factors into single maps and reveal the natural variability that are associates with the factors, its reveals the complex relationships that exist among the factors. A point worthwhile is that the entire surfaces of eco-climatic characteristics that can be incorporated into ecological consideration in the resource management strategy of the northern Nigeria. The integration of the factor unveils the union and intersection that exists between the moisture effectiveness zones. These derived eco-climatic indices are indispensable for identifying, delimiting and describing the state of the environment in quantitative terms. Finally, the study confirmed that dynamics in the eco-climatic parameters moisture effecttiveness zone is fundamental for the identification of the current state of the environment in Northern Nigeria. 
Consequently, necessitating the integration of derived remotely sense data for sustainable agriculture practices and other socio-economic in northern Nigeria. Principally, remotely sense data are fundament for the attainment of accurate, up-to-date and adequate information on the state of the environment. The technical procedure for doing this and the expected outcome are illustrated to demonstrate the potential for filling the gap created by outdated, inadequate and inaccurate information inherent in the use of existing classical climatic zones.

\section{ACKNOWLEDGEMENT}

Our appreciation goes to Nigeria Meteorological Agency (NIMET) and Environmental Management Program, Federal University of Technology Minna for providing the pre-requisite data for the research.

\section{REFERENCES}

Adefolalu DO (1986a). Further aspects of Sahelian drought as evident from rainfall regime of Nigeria. Meteorol. Atmos. Phys. 36(3-4):277295.

Adefolalu DO (1986b). Rainfall Trends in Nigeria. Theor. Appl. Climatol. 37: 205-219.

Adger W (2001). Scales of governance and environmental justice for adaptation and mitigation of climate change. J. Int. Dev. 13: 921-931.

David SGT, Chasca T (2005). Adaptation to Climate Change: Perspectives Across Scales. Glob. Environ. Chang. Part A. 15(2):115-124.

FAO (1996). Rome Declaration on World Food Security and World Food Summit Plan of Action. World Food Summit held in Rome Italt http://www.fao.org/docrep/003/w3613e/w3613e00 14/7/2013.

Hargreaves GH, Samani ZA (1985). Reference crop evapotranspiration from temperature. Appl. Eng. Agric. 1(2):96-99.

Kufoniyi O, Akinyed JO (2004). Mainstreaming Geospatial Information for Sustainable National Development in Nigeria. Proceeding ISPRS Congress, Istanbul,Turkey, http://www.isprs.org/proceedings/XXXV/co ngress/comm4/papers/360.pdf 14/07/13.
Lázaro R, Rodrigo L, Gutirrez FD, Puigdefabregas J (2001). Analysis of a 30-year rainfall record (1967-1997) in semi-arid SE Spain for implications on vegetation. J. Arid Environ. 48 (3): 373 - 395

López BC, Holmgren M, Sabate' A, Gracia CA (2008). Estimating Annual Rainfall Threshold for Establishment of Tree Species in Water-limited Ecosystems Using Tree-ring Data. J. Arid Environ. 72(5):602-611.

Peter HG (1998). Water in Crisis: Paths to Sustainable Use. Ecol. Appl. 8:571-579.

Srikantha $H$, Uditha $R$ (2004). Monitoring rainfall trends to predict adverse impacts-a case study from Sri Lanka (1964-1993). Glob. Environ. Chang. Part A. 14 (1):71-81.

Sui-Lin N, Chi-Fai C (2010) Issues and challenges in defeating world hunger. Trends Food Sci. Technol. 21(11):544-557.

Tennant WJ, Bruce CH (2002). Intra- Seasonal Rainfall Characteristics and their importance to the Seasonal Prediction. Int. J. Climatol. 22(9):1033-1048.

Usman MT (1999). An operational Index for Assessing Inter-annual, Rainfall, Variability and Agricultural droughts over the Nigeria Sahel. Afr. Climatol. Res. Ser. 3:22-32

Usman MT (2000) An Instability Index for monsoon onset characterization over the Nigerian Sahel. Environ. Rev. 3(2):367-379

Usman MT, Abdulkadir A (2012). On Determining the 'Real' Onset Date of Seasonal Rains in the Semi-Arid and Sub-Humid Areas of West Africa. Natural Hazard (NHAZ) (Online Jan. 2013 on SpringerLink:) DOI: 10.1007/s11069-012-0514-9. 